\title{
INTEGRATING NON-DESTRUCTIVE ION BEAM ANALYSIS METHODS AND AMS RADIOCARBON DATING FOR THE STUDY OF ANCIENT BRONZE STATUES
}

\author{
Gianluca Quarta $^{1,2} \cdot$ Lucio Calcagnile $^{1} \cdot$ Massimo Vidale $^{3}$
}

\begin{abstract}
Analytical methods based on particle accelerators are widely used in cultural heritage diagnostics and archaeological sciences from the absolute dating of organic materials by means of radiocarbon accelerator mass spectrometry (AMS) to the analysis of the elemental composition of a wide range of materials (metals, obsidians, pottery) via ion beam analysis (IBA) techniques. At CEDAD (Centre for Dating and Diagnostics), the accelerator facility of the University of Salento, AMS ${ }^{14} \mathrm{C}$ dating and PIXE (particle-induced X-ray emission)-PIGE (particle-induced gamma-ray emission) compositional analysis in external beam mode are combined to study certain archaeological materials. We present a review of the combined application of these analytical methods in the study of casting cores of the Riace bronzes, 2 classical Greek statues of extraordinary importance for the history of art.
\end{abstract}

\section{INTRODUCTION}

Accelerator-based analytical methods are well-established methodologies in the field of cultural heritage diagnostics. This is true both for accelerator mass spectrometry (AMS) radiocarbon dating and ion beam analysis (IBA) techniques. In particular, AMS ${ }^{14} \mathrm{C}$ dating has seen important advancements recently in terms of instrumental developments and in the definition of new approaches for sample preparation and data analysis (D'Elia et al. 2007; Gianfrate et al. 2007; Boaretto 2009; Bronk Ramsey 2009; Brock et al. 2010; Synal and Wacker 2010).

IBA methods have been largely applied in the analysis of cultural artifacts with dedicated and complex experimental setups developed in different laboratories worldwide (Menu et al. 1990; Demortier 2004; Mandò 2009). In fact, the extraction of high-energy particle beams in air through proper beam-extraction nozzles allows us to perform IBA compositional analyses at atmospheric pressure in a non-destructive way, and this overcomes the geometrical limitations associated with the use of vacuum chambers. These advantages make IBA techniques particularly suitable for the analysis of objects from cultural heritage, where non-destructive analyses and the possibility of performing compositional analyses without sampling is often mandatory.

Another advantage of IBA methods is the ability to obtain complementary compositional information by simultaneously detecting different interaction products of the beam with the analyzed material. Typically, the detection of characteristic X-rays (PIXE: particle-induced X-ray emission) emitted by atomic inner shell ionizations and nuclear gamma rays (PIGE: particle-induced gamma-ray emission) can provide information about light and heavy element compositions simultaneously. In previous work, the great potential offered by a combined AMS-IBA approach for the analysis of cultural objects and archaeological contexts has been demonstrated in different cases when the chronological information obtained by ${ }^{14} \mathrm{C}$ dating is also integrated with IBA compositional analysis results (Quarta et al. 2007). Successful examples of the synergy between these techniques have been shown in different cases. Examples include determination of the provenance of obsidian samples from ${ }^{14} \mathrm{C}$-dated Neolithic contexts in Anatolia and southern Italy (Butalag et al. 2008; Quarta et al. 2011), compositional analysis of golden artifacts from Bronze Age sites (Butalag et al. 2005), the study of the diagenetic state of cremated bones, and the study of ancient papyri (Fedi et al. 2010).

\footnotetext{
${ }^{1}$ CEDAD-Department of Engineering for Innovation, University of Salento, via per Monteroni, 73100 Lecce, Italy.

${ }^{2}$ Corresponding author. Email: Gianluca.quarta@unisalento.it.

${ }^{3}$ Department of Cultural Heritage, University of Padua, Piazza Capitanato 7, 35139 Padova, Italy.
}

(C) 2012 by the Arizona Board of Regents on behalf of the University of Arizona Proceedings of the 6th International Radiocarbon and Archaeology Symposium, edited by E Boaretto and N R Rebollo Franco RADIOCARBON, Vol 54, Nr 3-4, 2012, p 801-812 
In this paper, we present the results obtained by a combined IBA-AMS approach for the analysis of inner cores of the 2 classical Greek bronze statues, the "Riace bronzes." In this case, the aim of the analysis was to absolutely date the artifacts through ${ }^{14} \mathrm{C}$ analysis of organic residues found inside the cores and to explore the potential of a PIXE-PIGE approach for compositional information about the manufacture of the statues.

In 1972, 2 complete bronze statues were accidentally found underwater along the Ionian coast of Calabria in southern Italy. The 2 statues, named the "Riace bronzes" after the town on whose coast they were found, are labeled "statue A" and "statue B" and represent warriors or athletes of extraordinary importance for the history of art. The 2 artifacts underwent large restoration campaigns in Florence by the Sovrintendenza Archeologica of Tuscany (Formigli 1984) and in Reggio Calabria by the Istituto Centrale per il Restauro (ICR) (Micheli and Vidale 2003). In the latter ICR restoration work, the statues underwent extensive microexcavation by means of remote-controlled microcameras and microtools. The microexcavations enabled studying the inner structure of the statues and the extraction of large quantities ( $72 \mathrm{~kg}$ and $56 \mathrm{~kg}$ from statue $\mathrm{A}$ and $\mathrm{B}$, respectively) of the casting cores. The importance of these materials as source of information for the study of the 2 masterpieces was soon recognized (Lombardi and Vidale 1998). Essentially, the material extracted from the inner cores was expected to contribute to the solution of 3 main questions related to the statues: their techniques of casting (Micheli and Vidale 2003), their provenance, and dating.

For the dating, heavy irradiation of the 2 statues for radiographic purposes soon after their discovery prevented further dating of the casting cores by thermoluminescence. Nevertheless, the identification of significant quantities of organic residues embedded in the casting cores suggested the possibility of using AMS ${ }^{14} \mathrm{C}$ dating to confirm of the date of the 2 statues, which was expected to be the 5 th century $\mathrm{BC}$ based on stylistic considerations. In a previous study, the main issues related to the application of AMS ${ }^{14} \mathrm{C}$ dating to these samples, and in particular the problem of sample selection and chemical processing, have been discussed and preliminary results presented (Calcagnile et al. 2010). This article presents new ${ }^{14} \mathrm{C}$ data from samples recovered from different points in the statues together with a conclusive analysis of the results.

To determine the composition of the casting cores mineralogical, petrographic, and paleontological investigations have already been performed as well as analysis of their elemental composition by means of instrumental neutron activation analysis (INAA), inductively coupled plasma mass spectrometry (ICP-MS), and infrared spectrometry (Lombardi and Vidale 1998). Analytical work revealed that in both statues the armpits and the neck joins contained lumps of casting-soldering clays, which were chemically quite distinct from the casting clay core of the rest of the bodies, possibly because these peculiar materials were reputed by ancient craftsmen as having optimal and specific metallurgical potential. Moreover, the right arm of statue B contained residues of a clay core that, based upon its petrographic and mineralogical associations and chemical trace elements, suggested a more recent origin for this part of the statue.

The aim of this paper is to investigate the suitability, the advantages, and the limitations of a combined PIXE-PIGE approach for the study of samples like the Riace bronzes. Both INAA and PIXEPIGE analyses are widely used for elemental analysis of materials in cultural heritage diagnostics such as coins, obsidians, jewelry items, and pottery mainly due to their high analytical sensitivity and the possibility to perform multielemental analyses in a non-destructive way, without sample preparation. Nevertheless, while INAA is typically a bulk analysis method, PIXE-PIGE analysis is a surface analysis technique. This can be seen as a relevant advantage of INAA with respect to PIXE-PIGE analyses, when, as is the case with the casting cores, an average composition for a com- 
plex matrix has to be determined. However, when crushing and mixing of the samples is possible, as in the present study, also IBA methods allow to obtain compositional information that can be representative of the bulk concentration of the samples. The PIXE-PIGE approach, on the other hand, offers as advantages easier implementation and the absence of activation, and thus delayed radioactivity, in the analyzed samples.

\section{METHODS}

Overall, 47 specimens of the casting cores, sampled during the microexcavations carried out by the Istituto Centrale per il Restauro (ICR), were used for the present study. The samples were all preliminarily inspected with an optical microscope in order to select those containing sufficient organic material to be used for AMS ${ }^{14} \mathrm{C}$ dating. Several different types of organic residues were identified in the samples, such as vegetal remains, charred wood, and animal hair. Table 1 lists the samples (13 from statue A, 12 from statue B) from which organic residues were obtained. Unfortunately, for the casting cores extracted from inside the right arm of statue B, it was not possible to extract enough material for dating.

Table 1 List of the organic samples selected from casting cores of the Riace bronzes for AMS ${ }^{14} \mathrm{C}$ dating analyses, including the results already published in Calcagnile et al. (2010).

\begin{tabular}{llll}
\hline Sample ID & Lab code & Sample material & ${ }^{14}$ C age (BP) \\
\hline Statue A & & & \\
US2167 Q140-145 & LTL2527A & Charred wood & $2359 \pm 45$ \\
US2203 Q160-165 & LTL2528A & Charred wood & $2482 \pm 45$ \\
US2203 Q160-165 & LTL2528B & Seed & $2319 \pm 55$ \\
Right Leg US2082 Q75-80 & LTL2533A & Charred wood & $2636 \pm 65$ \\
Right Leg Q90-95 & LTL3348A & Charcoal & $2388 \pm 45$ \\
Right Leg Q90-95 & LTL3348B & Charcoal & $2365 \pm 95$ \\
Right Leg Q90-95 & LTL3348C & Charcoal & $2364 \pm 75$ \\
Q150-155 & LTL2526A & Charcoal & $3088 \pm 40$ \\
Q150-155 & LTL2526B & Charcoal & $2671 \pm 50$ \\
Q155-160 & LTL3345A & Vegetal remains & $3112 \pm 150$ \\
Right hip QT120-125 US2156 & LTL3502A & Organic material & $2510 \pm 80$ \\
Right hip QT120-125 US2156 & LTL3502B & Organic material & $2355 \pm 45$ \\
Right hip QT120-125 US2156 & LTL3502C & Organic material & $2360 \pm 45$ \\
Statue B & & & \\
US2283 & LTL2525A & Charred wood & $2381 \pm 40$ \\
US2283 & LTL2525B & Seed & $2459 \pm 40$ \\
US2283 & LTL2525C & Charred wood & $2460 \pm 50$ \\
US673 Q170-200 & LTL2545A & Charred wood & $2413 \pm 45$ \\
US145 & LTL3029A & Animal hair & $2353 \pm 45$ \\
US478 & LTL3030A & Animal hair & $2410 \pm 40$ \\
US516 & LTL3031A & Animal hair & $2420 \pm 40$ \\
US131 & LTL3505A & Charred wood & $2345 \pm 45$ \\
US131 & LTL3505B & Charred wood & $2324 \pm 40$ \\
US131 & LTL3505C & Charred wood & $2360 \pm 40$ \\
US131 & LTL3505D & Charred wood & $2375 \pm 40$ \\
US131 & LTL3505E & Charred wood & $2390 \pm 50$ \\
\hline & & &
\end{tabular}


The organic materials were manually isolated under the microscope from the inorganic matrix and underwent chemical processing for contamination removal following the acid-alkali-acid protocol routinely used in CEDAD (D'Elia et al. 2004). The purified material was then converted to carbon dioxide by combustion at $900{ }^{\circ} \mathrm{C}$ in sealed quartz tubes, cryogenically purified, then catalytically reduced to graphite by using $\mathrm{H}_{2}$ as reducing agent and $\mathrm{Fe}$ powder as catalyst. The ${ }^{14} \mathrm{C}$ age was then measured with the AMS spectrometer installed at CEDAD (Centre for Dating and Diagnostics), University of Salento, Lecce, Italy (Calcagnile et al. 2005).

Twenty-two casting core samples (9 from statue A, 13 from statue B) were also selected for PIXEPIGE measurements, which were carried out at the external beam IBA setup at CEDAD (Table 2). Since IBA compositional analyses were concerned with the analysis of original bulk composition of the casting cores, all the samples were prescreened using the optical microscope in order to remove evident traces of the original metal alloy or of its corrosion products. Selected samples, with masses of $\sim 200 \mathrm{mg}$, were then crushed to powder by pestle and mortar, mechanically homogenized, and pressed in 13-mm-diameter pellets at $7.5 \mathrm{kN} / \mathrm{mm}^{2}$ pressure. The samples were then irradiated at atmospheric pressure with a 3.7-MeV, $1-\mathrm{nA}, \sim 2-\mathrm{mm}$ proton beam extracted into air through a 8- $\mu \mathrm{m}-$ thick Kapton window. Typical irradiation time was $15 \mathrm{~min}$ per sample. Characteristic X-rays and gamma rays were simultaneously detected by using a $\mathrm{Si}(\mathrm{Li})$ detector (Canberra model 80160 ) with an active area of $80 \mathrm{~mm}^{2}$ and a resolution of $150 \mathrm{eV}$ at $5.9 \mathrm{keV}(\mathrm{Mn} \mathrm{K}$ line with a shaping time of $12 \mu \mathrm{s}$ ) and a hyperpure Ge detector (Canberra model GC6022) with $60 \%$ of relative efficiency and energy resolution of $2.2 \mathrm{keV}$ at $1.33 \mathrm{MeV}$. A $90-\mu$ m-thick Al pinhole filter with a $0.7-\mathrm{mm}$ hole was placed in front of the $\mathrm{Si}(\mathrm{Li})$ detector in order to reduce the intense signal from light elements and enhance the sensitivity for heavy elements. The samples were scanned over a $1 \times 1 \mathrm{~cm}^{2}$ area during irradiation, by using remote-controlled X-Y step motors, to obtain information on the average composition of the samples. PIXE spectra and quantitative analyses were carried out via GUPIXWIN software (Campbell et al. 2010). In particular, the "matrix solution" procedure in this code was used by considering $\mathrm{C}$ and $\mathrm{O}$ as "invisible" elements. For PIGE analysis, spectra were acquired by using the Genie 2000 v 3.0 data acquisition software (CANBERRA), which was also used for background subtraction and for determination of the peak areas. In fact, quantitative PIGE analyses of thick samples presents more difficulties with respect to PIXE, due to the strong energy dependence of the gamma ray production cross-sections on the proton beam energy, which decreases as the protons lose energy along their path into the sample (Mateus et al. 2004). For this purpose, PIGE quantitative measurements were referred to geological standards, measured together with the samples, and with a similar chemical composition. By using this approach, PIGE quantitative results with an accuracy of $\sim 5 \%$ are achievable (Cohen et al. 2002).

Table 2 List of samples selected from casting cores of the Riace bronzes for PIXE-PIGE compositional analyses.

\begin{tabular}{ll}
\hline Sample ID & Lab code \\
\hline Statue A & \\
Q150-155 & LTL2526A \\
US2167 Q140-145 & LTL2527A \\
US2203 Q160-165 & LTL2528A \\
Right Armpit & LTL2530A \\
Left Chest, Q110/105 & LTL2531A \\
Right Arm, US2082 Q7580 & LTL2533A \\
Right Hip, Q120-125 US2156 & LTL3502A \\
Right Leg, Q75-80 & LTL3499A \\
Left Leg, Q55-60 & LTL3500A
\end{tabular}


Table 2 List of samples selected from casting cores of the Riace bronzes for PIXE-PIGE compositional analyses. (Continued)

\begin{tabular}{ll}
\hline Sample ID & Lab code \\
\hline Statue B & \\
US2283 & LTL2525A \\
US677 & LTL2532A \\
Q150-160 & LTL2538A \\
Right Arm & LTL2535A \\
Right Arm & LTL2540A \\
Right Arm & LTL2541A \\
US586 Q155-160 & LTL2543A \\
US673 Q170-200 & LTL2545A \\
US145 & LTL3029A \\
US478 & LTL3030A \\
US101 & LTL3503A \\
Q125 US352 & LTL3506A \\
Q14-145 & LTL3509A \\
\hline
\end{tabular}

\section{RESULTS AND DISCUSSION}

\section{AMS Radiocarbon Dating Analyses}

The AMS ${ }^{14} \mathrm{C}$ dating results are reported as conventional ${ }^{14} \mathrm{C}$ ages in Table 1 for both statues. Conventional ${ }^{14} \mathrm{C}$ determinations were converted to calendar ages by using the $\mathrm{OxCal} v 4.0$ software (Bronk Ramsey 2009) and the IntCal09 calibration curve (Reimer et al. 2009). Calibrated data are shown in Figures 1 and 2 for statues $\mathrm{A}$ and $\mathrm{B}$, respectively. The ${ }^{14} \mathrm{C}$ data obtained for each statue show a remarkable consistency between them. The only exceptions are the outlying data corresponding to 3 samples (LTL2526A, LTL2526B, and LTL3345A) from statue A. In fact, these could be explained as due to the presence of "old" organic material that was included in the material used for production of the casting cores. These data were not included in the following analysis, which combines the results by using the $R$ _Combine function in OxCal. The results of the combination of $10{ }^{14} \mathrm{C}$ ages for statue $\mathrm{A}$ and 12 ages for statue $\mathrm{B}$ are reported in Figures $1 \mathrm{~b}$ and $2 \mathrm{~b}$, respectively. The combined chronological ranges correspond to the periods $512-398 \mathrm{BC}$ and $511-400 \mathrm{BC}$ for statues $A$ and $B$, respectively, with a probability of $95.4 \%$. The 2 statues thus both date to the 5 th century $\mathrm{BC}$, confirming the widely accepted dating of the artifacts based on stylistic considerations, which ascribe statue $A$ to the period $470-460 \mathrm{BC}$ and statue $\mathrm{B}$ to $440-430 \mathrm{BC}$.

We note here that, despite the large number of analyzed samples and the consistency of the results, which produced a standard deviation on the combined ${ }^{14} \mathrm{C}$ age of only 18 and $13 \mathrm{yr}$ for statues $\mathrm{A}$ and $\mathrm{B}$, respectively, the conventional ${ }^{14} \mathrm{C}$ ages are essentially indistinguishable. Furthermore, the calibrated time ranges, at $95.4 \%$ confidence level, extend for about a century, caused by the flat shape of the ${ }^{14} \mathrm{C}$ calibration curve in the period between the 7 th and 5th centuries BC (Blackwell et al. 2006). Hence, the achievable chronological resolution does not allow us to check the expected difference of $\sim 30 \mathrm{yr}$ between the age of the 2 statues. The application of different sampling and data analysis strategies, such as those resulting from the application of Bayesian methods for data reduction, are usually helpful for enhancing the chronological resolution in such "problematic" time periods (Bronk Ramsey 2009). However, these approaches are not applicable in this particular case due 
to the intrinsic difficulties related in the definition of proper chronological constraints to be used as a priori information in Bayesian analysis of the data.
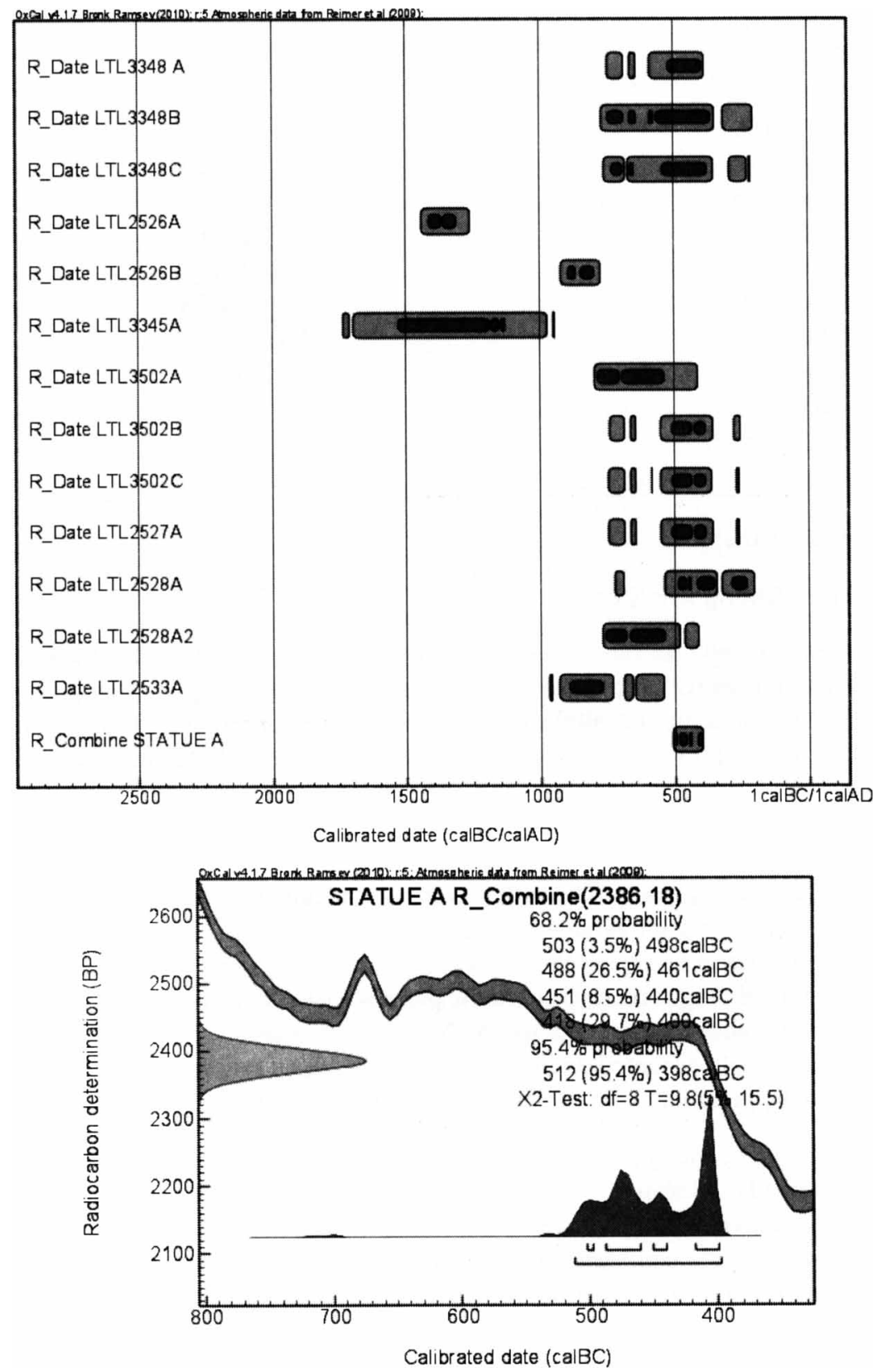

Figure 1 a) Summary (above) of calibration of the ${ }^{14} \mathrm{C}$ data obtained for statue $\mathrm{A}$ and $\mathrm{b}$ ) statistical combination of the results (below). 

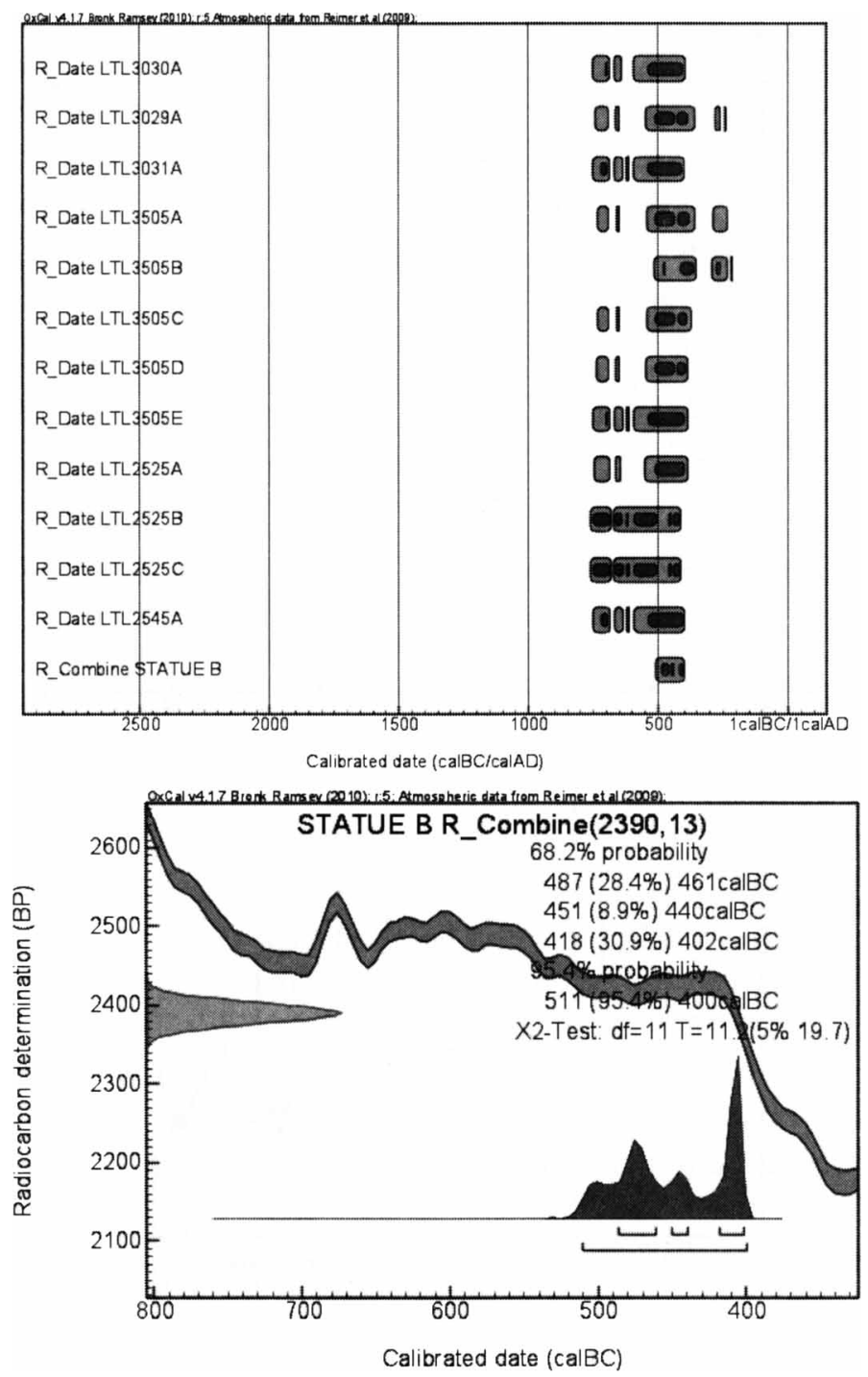

Figure 2 a) Summary (above) of calibration of the ${ }^{14} \mathrm{C}$ data obtained for statue $\mathrm{B}$ and $\mathrm{b}$ ) statistical combination of the results (below).

\section{IBA Analyses}

Typical PIXE and PIGE spectra obtained for the samples are shown in Figure 3 with the indication of the elements detected by PIXE: $\mathrm{Cl}, \mathrm{K}, \mathrm{Ca}, \mathrm{Ti}, \mathrm{Mn}, \mathrm{Fe}, \mathrm{Cu}, \mathrm{Zn}, \mathrm{As}, \mathrm{Rb}, \mathrm{Sr}, \mathrm{Y}, \mathrm{Zr}, \mathrm{Pb}, \mathrm{Sn}$; and by PIGE: F, Na, Al, and Si. Among the detected elements some, which also showed a strong variability within the samples, can be surely considered as "contamination" of the original casting core composition, such as those associated with the original bronze alloy or with its corrosion products $(\mathrm{Cu}, \mathrm{Sn}$, and $\mathrm{Pb}$ ) and $\mathrm{Cl}$, likely associated with the presence of sea salt. These elements were thus not used to discriminate the compositions of the statue cores. 

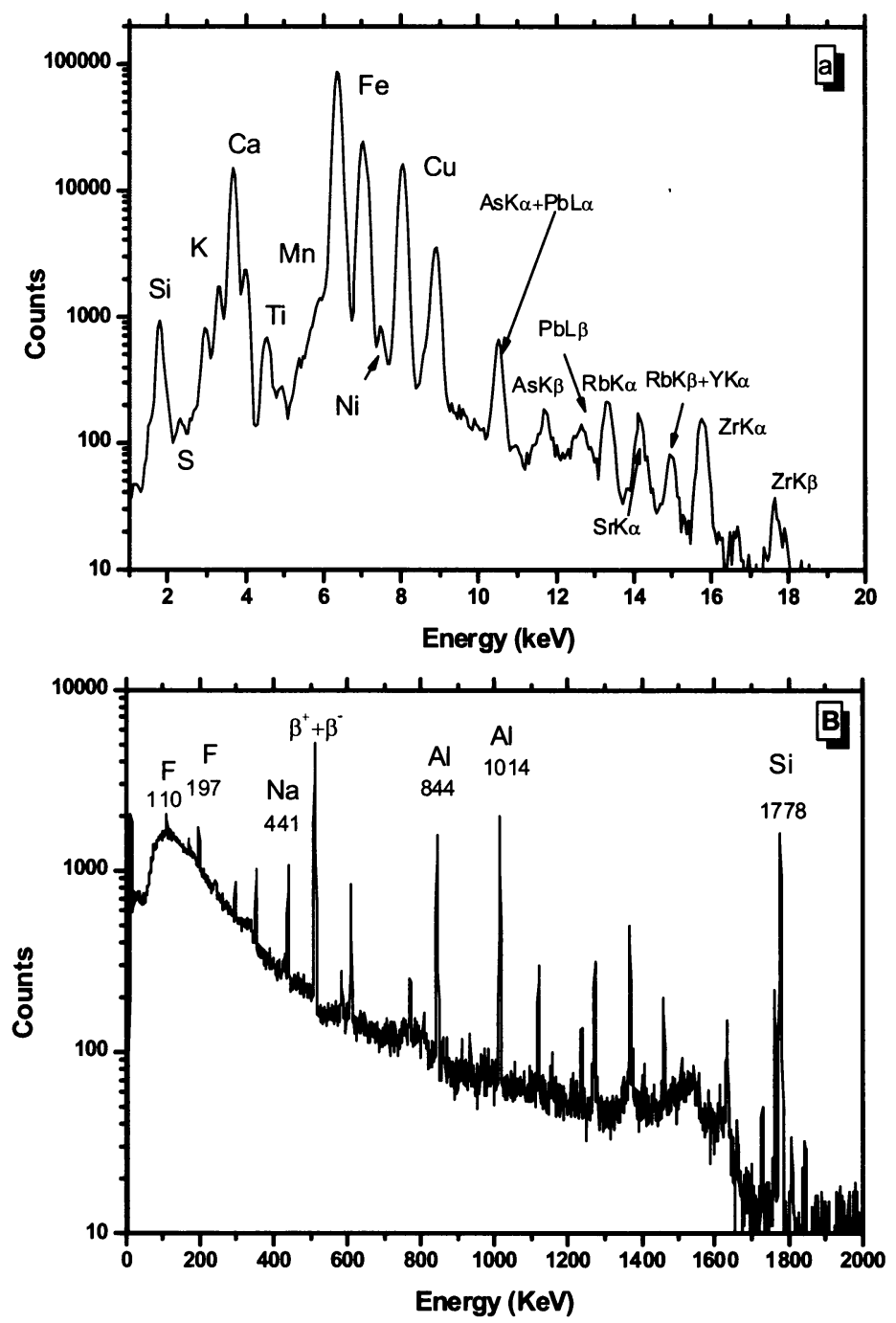

Figure 3 Typical PIXE (a) and PIGE (b) spectra for the analyzed samples

Table 3 lists the measured compositional ranges in terms of major, minor, and trace elements for the 2 statues and for the samples taken from the right arm of statue B. The ranges determined are also shown in Figure 4. Our analysis of the compositional data confirms previous analytical studies (Lombardi et al. 2003: Figures 139-144) and their conclusions, that the main constituents of the casting material are $\mathrm{Ca}$ and $\mathrm{Si}$. This suggests that the base material was in both cases silica- and calcium-rich silty marls, but with significant differences between the 2 statues. Statue A shows a higher concentration of silica and of other elements such as $\mathrm{Al}$ and $\mathrm{Fe}$. In fact, $\mathrm{Al}_{2} \mathrm{O}_{3}$ and $\mathrm{Fe}_{2} \mathrm{O}_{3}$ are both associated with the silicate phase as also demonstrated by the significant correlation found between $\mathrm{Al}_{2} \mathrm{O}_{3}$ and $\mathrm{SiO}_{2}\left(r^{2}=0.91\right)$ and between $\mathrm{Fe}_{2} \mathrm{O}_{3}$ and $\mathrm{SiO}_{2}\left(r^{2}=0.67\right)$. These higher concentrations are likely caused by the addition of quartz-rich temper in the casting cores as suggested in previous studies based on chemical analyses (Lombardi and Vidale 1998; Lombardi et al. 2003). Also, the Ca concentration is different between the 2 statues, with a ratio between the $\mathrm{CaO}$ concentration in statue $\mathrm{A}$ and $\mathrm{B}$ of approximately 1:2. When looking at the trace element composition, the main differences 
Table 3 Measured elemental concentrations for the 2 statues.

\begin{tabular}{clcc|cc|cc}
\hline & & \multicolumn{2}{c|}{ Statue $\mathrm{A}$} & \multicolumn{2}{c|}{ Statue B } & \multicolumn{2}{c}{ Right arm statue B } \\
\cline { 2 - 8 } Unit & Element & Average & Range & Average & Range & Average & Range \\
\hline \multirow{2}{*}{ wt \% } & $\mathrm{F}$ & 0.06 & $0.04-0.07$ & 0.05 & $0.03-0.08$ & 0.03 & $0.02-0.04$ \\
& $\mathrm{SiO}_{2}$ & 48 & $42-54$ & 27 & $24-30$ & 17 & $13-21$ \\
& $\mathrm{Na}_{2} \mathrm{O}$ & 0.4 & $0.3-0.6$ & 0.3 & $0.3-0.4$ & 0.30 & $0.2-0.5$ \\
& $\mathrm{Al}_{2} \mathrm{O}_{3}$ & 9.5 & $8.5-10.3$ & 5.9 & $5.1-6.4$ & 2.3 & $2.0-2.6$ \\
& $\mathrm{SO}_{4}$ & 0.6 & $0.4-1.1$ & 0.4 & $0.2-0.7$ & 21 & $19-22$ \\
& $\mathrm{~K}_{2} \mathrm{O}$ & 1.5 & $1.2-1.8$ & 1.3 & $1.1-1.6$ & 0.6 & $0.5-0.7$ \\
& $\mathrm{CaO}$ & 16 & $12-18$ & 31 & $28-35$ & 20 & $19-21$ \\
& $\mathrm{TiO}$ & 0.5 & $0.4-0.6$ & 0.3 & $0.2-0.4$ & 0.08 & $0.07-0.09$ \\
& $\mathrm{MnO}$ & 0.03 & $0.02-0.05$ & 0.05 & $0.04-0.06$ & 0.02 & $0.01-0.03$ \\
& $\mathrm{Fe} \mathrm{O}_{3}$ & 5.2 & $3.2-12.4$ & 2.5 & $2.1-3.4$ & 0.7 & $0.6-0.8$ \\
$\mathrm{ppm}$ & $\mathrm{Ni}$ & 80 & $50-90$ & 68 & $53-89$ & 53 & $46-60$ \\
& $\mathrm{Cu}$ & 3100 & $190-13,000$ & 1600 & $50-5000$ & 5800 & $3000-9600$ \\
$\mathrm{Zn}$ & 40 & $20-50$ & 30 & $20-50$ & 40 & $35-45$ \\
$\mathrm{As}$ & 100 & $90-130$ & $<10$ & - & $<10$ & - \\
$\mathrm{Rb}$ & 60 & $50-70$ & 51 & $40-60$ & $<10$ & - \\
$\mathrm{Sr}$ & 60 & $40-100$ & 479 & $370-590$ & 220 & $200-240$ \\
& $\mathrm{Y}$ & 20 & $17-30$ & 14 & $10-20$ & $<10$ & - \\
$\mathrm{Zr}$ & 160 & $100-300$ & 57 & $40-80$ & 30 & $20-40$ \\
$\mathrm{Sn}$ & - & $<20-1000$ & - & $<20-100$ & 130 & $80-180$ \\
$\mathrm{~Pb}$ & 90 & $30-200$ & 54 & $10-380$ & 2300 & $2200-2400$ \\
\hline
\end{tabular}

between the 2 statues are those related to the $\mathrm{Sr}$ and $\mathrm{Zr}$ concentrations. Sr shows a strong correlation with $\mathrm{CaO}\left(r^{2}=0.93\right)$ (Figure 5), with the $\mathrm{Ca}-\mathrm{Sr}$ binary plot that clearly allows to distinguish between the 2 statues and the right arm of statue B. A ratio of 1:8 is measured between the $\mathrm{Sr}$ concentration in statues $A$ and $B$ (except the right arm).

Particularly interesting are the compositional results of the core in the right arm of the B statue. This part was expected to be the result of a restoration or an alteration of the original statue based on stylistic considerations. The composition of the inner cores in the right arm of statue B is in fact significantly different from that of the rest of the statue. In fact, all the analyzed samples for the right arm of sample B showed a S concentration significantly higher than that measured for the rest of the statue. This might be considered an indication of a gypsum-rich matrix that significantly differs from the matrix of statue B (Formigli 1984). Moreover, most probably gypsum was an original component of the soldering clay cores used while applying or manipulating the arms of statue B during its ancient modification (Lombardi et al. 2003:169).

A principal component analysis (PCA) was also carried out on the measured composition for the samples analyzed in order to confirm the clustering of the samples. The concentration of $\mathrm{F}, \mathrm{Na}_{2} \mathrm{O}$, $\mathrm{Al}_{2} \mathrm{O}_{3}, \mathrm{SiO}_{2}, \mathrm{~K}_{2} \mathrm{O}, \mathrm{CaO}, \mathrm{TiO}_{2}, \mathrm{MnO}, \mathrm{Fe}_{2} \mathrm{O}_{3}, \mathrm{Ni}, \mathrm{Zn}, \mathrm{As}, \mathrm{Rb}, \mathrm{Sr}, \mathrm{Y}, \mathrm{Zr}$, and Pb were used for the analysis. In Table 4, the factor loadings of the first 2 principal components are given within parentheses; only elements with values $>0.5$ are reported. The percentage of variance explained by each component is also listed. The results of this analysis are depicted in Figure 6, which shows the graph corresponding to the 2 first principal components (axes F1 and F2) and highlighting the $>76 \%$ of the total variance of the data set. The analysis clearly allows us to cluster the samples into 3 groups corresponding to the statue $A$, statue $B$, and the right arm of statue $B$. 

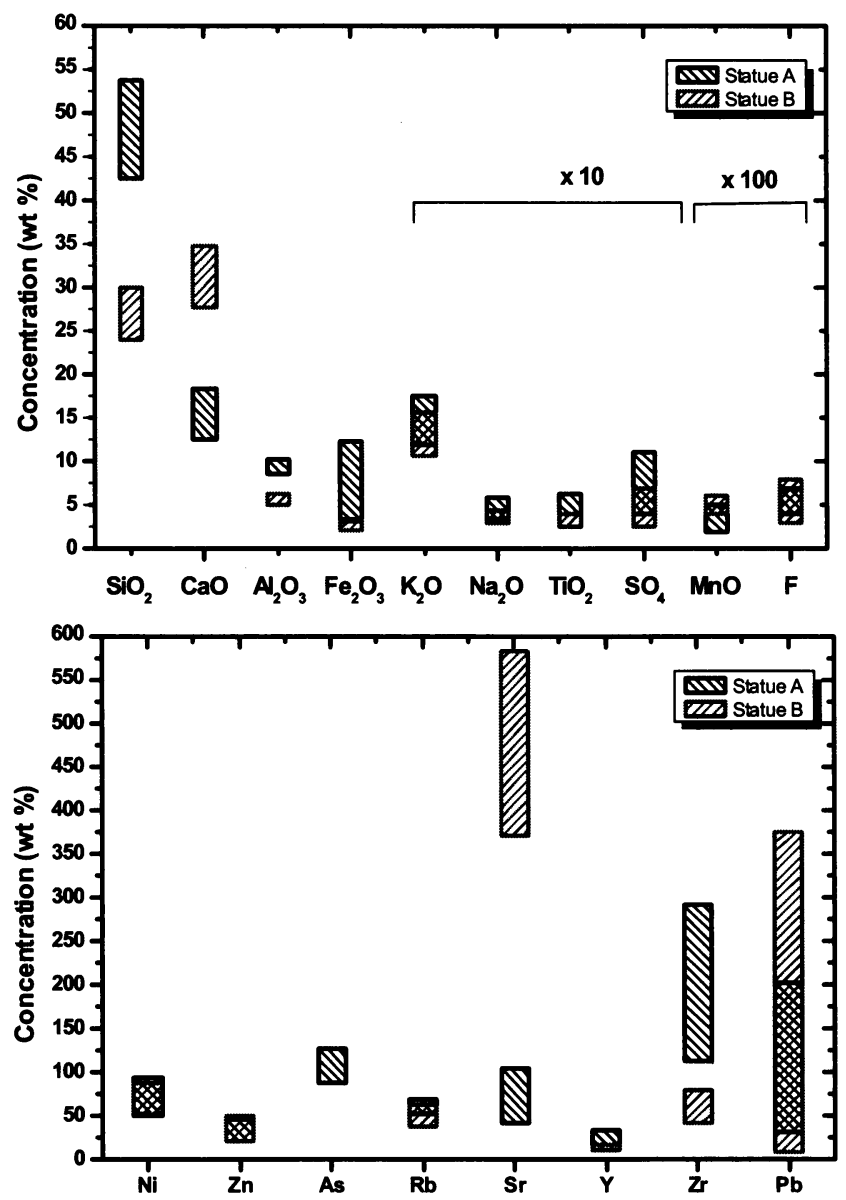

Figure 4 Major, minor, and trace element compositional ranges as measured by PIXE and PIGE for samples taken from casting cores of the 2 statues.

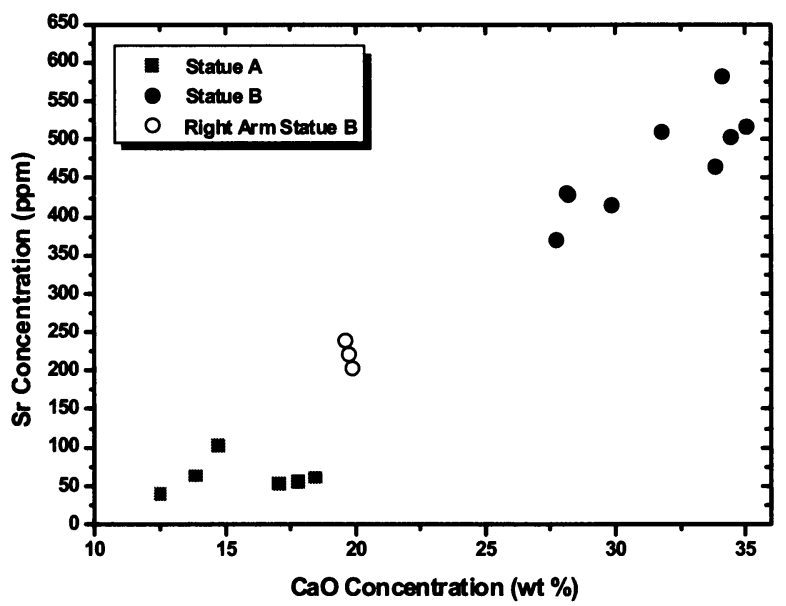

Figure 5 Correlation between the $\mathrm{CaO}$ and $\mathrm{Sr}$ concentrations for the analyzed samples. 
Table 4 Factor loadings obtained for the first 2 principal components; only those $>0.5$ are listed.

\begin{tabular}{ll}
\hline Component 1 & Component 2 \\
\hline $\mathrm{F}(0.78)$ & $\mathrm{CaO}(0.86)$ \\
$\mathrm{NaO}_{2}(0.71)$ & $\mathrm{MnO}(0.87)$ \\
$\mathrm{Al}_{2} \mathrm{O}_{3}(0.98)$ & $\mathrm{Sr}(0.8)$ \\
$\mathrm{SiO}_{2}(0.94)$ & \\
$\mathrm{K}_{2} \mathrm{O}(0.81)$ & \\
$\mathrm{TiO}_{2}(0.95)$ & \\
$\mathrm{Fe}_{2} \mathrm{O}_{3}(0.69)$ & \\
$\mathrm{Ni}^{(0.71)}$ & \\
$\mathrm{As}(0.90)$ & \\
$\mathrm{Rb}(0.85)$ & \\
$\mathrm{Y}(0.79)$ & \\
$\mathrm{Zr}(0.85)$ & Variance $21.02 \%$ \\
Variance $55.34 \%$ & \\
\hline
\end{tabular}

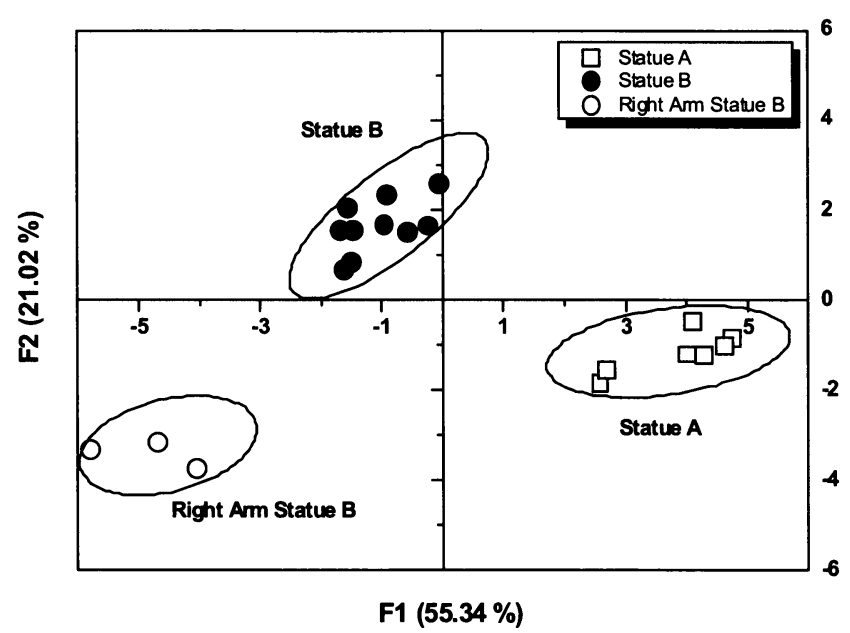

Figure 6 Results of the principal component analysis (PCA)

\section{CONCLUSIONS}

The casting cores of 2 important and well-preserved masterpieces of Greek classical art have been analyzed by using accelerator-based methods at CEDAD. In particular, organic residues were selected and sampled from the 2 statues and submitted for AMS ${ }^{14} \mathrm{C}$ dating. The results confirmed the expected date of the 5th century BC, concordant with what was suggested based on historical and stylistic considerations. Samples from the casting cores were also analyzed by PIXE and PIGE in external beam mode to determine the major and trace element compositions of the studied samples. The results showed marked compositional differences between the 2 statues with respect to both major and trace elements. IBA results are also coherent with previous studies indicating 2 different microenvironments for the provenance of casting cores of the 2 statues.

The right arm of statue $\mathrm{B}$ had a chemical composition significantly different from the rest of the statue. This is consistent with the hypothesis that this part of the statue is a restoration or alteration of the original statue as inferred based on stylistic considerations. Unfortunately, it was not (yet) possible to select sufficient organic material for ${ }^{14} \mathrm{C}$ dating of this part of the artifact, although further samples have been obtained and future analyses are already planned. 


\section{REFERENCES}

Blackwell PG, Buck CE, Reimer PJ. 2006. Important features of the new radiocarbon calibration curves. Quaternary Science Reviews 25(5-6):408-13.

Boaretto E. 2009. Dating materials in good archaeological contexts: the next challenge for radiocarbon analysis. Radiocarbon 51(1):275-81.

Brock F, Higham T, Bronk Ramsey C. 2010. Pre-screening techniques for identification of samples suitable for radiocarbon dating of poorly preserved bones. Journal of Archaeological Science 37(4):855-65.

Bronk Ramsey C. 2009. Bayesian analysis of radiocarbon dates. Radiocarbon 51(1):337-60.

Butalag K, Demortier G, Quarta G, Muscogiuri D, Calcagnile L, Pagliara C, Maggiulli G, Mazzotta C. 2005. Checking the homogeneity of gold artefacts of the final Bronze Age found in Roca Vecchia, Italy by proton induced X-ray emission. Nuclear Instruments and Methods in Physics Research B 240(1-2):565-9.

Butalag K, Calcagnile L, Quarta G, Maruccio L, D'Elia M. 2008. PIXE analysis of obsidian tools from radiocarbon dated archaeological contexts. Nuclear Instruments and Methods in Physics Research B 266(10): 2353-7.

Calcagnile L, Quarta G, D'Elia M. 2005. High-resolution accelerator-based mass spectrometry: precision, accuracy and background. Applied Radiation and Isotopes 62(4):623-9.

Calcagnile L, D'Elia M, Quarta G, Vidale M. 2010. Radiocarbon dating of ancient bronze statues: preliminary results from the Riace statues. Nuclear Instruments and Methods in Physics Research B 268(7-8): 1030-3.

Campbell JL, Boyd NI, Grassi N, Bonnick P, Maxwell JA. 2010. The Guelph PIXE software package IV. $\mathrm{Nu}$ clear Instruments and Methods in Physics Research B 268(20):3356-63.

Cohen D, Siegele R, Orlic I, Stelcer E. 2002. Long-term accuracy and precision of PIXE and PIGE measurements for thin and thick sample analyses. Nuclear Instruments and Methods in Physics Research B 189(14):81-5.

D’Elia M, Calcagnile L, Quarta G, Rizzo A, Sanapo C, Laudisa M, Toma U, Rizzo A. 2004. Sample preparation and blank values at the AMS radiocarbon facility of the University of Lecce. Nuclear Instruments and Methods in Physics Research B 223-224:278-83.

D'Elia M, Gianfrate G, Quarta G, Giotta L, Giancane G, Calcagnile L. 2007. Evaluation of possible contamination sources in the ${ }^{14} \mathrm{C}$ analysis of bone samples by FTIR spectroscopy. Radiocarbon 49(2):201-10.

Demortier G. 2004. Proceedings of the "E. Fermi" International School of Physics, Physics Methods in Archaeometry. Amsterdam: IOS Press.

Fedi ME, Carraresi L, Grassi N, Migliori A, Taccetti F, Terrasi F, Mandò PA. 2010. The Artemidorus papyrus: solving an ancient puzzle with radiocarbon and ion beam analysis measurements. Radiocarbon 52(2): 356-63.

Formigli E. 1984. La tecnica di costruzione delle statue di Riace. In: Borrelli-Pelagatti V, editor. Due Bronzi da Riace. Rinvenimento, restauro, analisi e ipotesi di interpretazione. Rome: Bolettino d'Arte, Serie Speciale 3. p 107-42.

Gianfrate G, D'Elia M, Quarta G, Giotta L, Valli L, Calcagnile L. 2007. Qualitative application based on IR spectroscopy for bone sample quality control in radiocarbon dating. Nuclear Instruments and Methods in Physics Research B 259(1):316-9.

Lombardi G, Vidale M. 1998. From the shell to its content: the casting cores of the two bronze statues from Riace (Calabria, Italy). Journal of Archaeological Science 25(11):1055-66.

Lombardi G, Bianchetti P, Vidale M. 2003. Esami relativi alle terre di fusione. In: Melucco Vaccaro A, De Palma G, editors. I Bronzi di Riace. Restauro come Conoscenza. Volume 1. Rome: Artemide. p 131-72.

Mandò PA. 2009. INFN-LABEC-nuclear techniques for cultural heritage and environmental applications. Nuclear Physics News 19(1):5-12.

Mateus R, Jesus AP, Ribeiro JP. 2004. Quantitative analysis of light elements in thick samples by PIGE. $\mathrm{Nu}$ clear Instruments and Methods in Physics Research B 219-220:519-23.

Menu M, Calligaro T, Salomon J, Amsel G, Moulin J. 1990. The dedicated accelerator-based IBA facility AGLAE at the Louvre. Nuclear Instruments and Methods in Physics Research B 45(1-4):610-4.

Micheli M, Vidale M. 2003. Scavo dell'interno delle due statue. In: Melucco Vaccaro A, De Palma G, editors. I Bronzi di Riace. Restauro come Conoscenza. Volume 2. Rome: Artemide.

Quarta G, Butalag K, Calcagnile L, D'Elia M. 2007. Il nuovo Cimento B. Società Italiana di Fisica 122:773-84.

Quarta G, Maruccio L, Calcagnile L. 2011. Provenance studies of obsidians from Neolithic contexts in Southern Italy by IBA (ion beam analysis) methods. $\mathrm{Nu}$ clear Instruments and Methods in Physics Research B 269(24):3102-5.

Reimer PJ, Baillie MGL, Bard E, Bayliss A, Beck JW, Blackwell PG, Bronk Ramsey C, Buck CE, Burr GS, Edwards RL, Friedrich M, Grootes PM, Guilderson TP, Hajdas I, Heaton TJ, Hogg AG, Hughen KA, Kaiser KF, Kromer B, McCormac FG, Manning SW, Reimer RW, Richards DA, Southon JR, Talamo S, Turney CSM, van der Plicht J, Weyhenmeyer CE. 2009. IntCal09 and Marine09 radiocarbon age calibration curves, 0-50,000 years cal BP. Radiocarbon 51(4): 1111-50.

Synal H-A, Wacker L. 2010. AMS measurement technique after 30 years: possibilities and limitations of low energy systems. Nuclear Instruments and Methods in Physics Research B 268(7-8):701-7. 